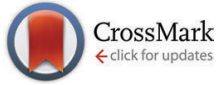

Cite this: Phys. Chem. Chem. Phys., 2015, 17, 29124

Received 6th August 2015, Accepted 5th October 2015

DOI: $10.1039 / \mathrm{c} 5 \mathrm{cp} 04656 \mathrm{~d}$

www.rsc.org/pccp

\section{A structural and physical study of sol-gel methacrylate-silica hybrids: intermolecular spacing dictates the mechanical properties $\uparrow$}

\author{
Anthony L. B. Maçon, ${ }^{a}$ Samuel J. Page, ${ }^{b}$ Justin J. Chung, ${ }^{a}$ Nadav Amdursky, ${ }^{a}$ \\ Molly M. Stevens, ${ }^{\text {acd }}$ Jonathan V. M. Weaver $\ddagger^{\mathrm{a}}$ John V. Hanna*b and \\ Julian R. Jones*a
}

\begin{abstract}
Sol-gel hybrids are inorganic/organic co-networks with nanoscale interactions between the components leading to unique synergistic mechanical properties, which can be tailored, via a selection of the organic moiety. Methacrylate based polymers present several benefits for class II hybrids (which exhibit formal covalent bonding between the networks) as they introduce great versatility and can be designed with a variety of chemical side-groups, structures and morphologies. In this study, the effect of high cross-linking density polymers on the structure-property relationships of hybrids generated using poly(3-trimethoxysilylpropyl methacrylate) (pTMSPMA) and tetraethyl orthosilicate (TEOS) was investigated. The complexity and fine scale of the co-network interactions requires the development of new analytical methods to understand how network evolution dictates the wide-ranging mechanical properties. Within this work we developed data manipulation techniques of acoustic-AFM and solid state NMR output that provide new approaches to understand the influence of the network structure on the macroscopic elasticity. The concentration of PTMSPMA in the silica sol affected the gelation time, ranging from $2 \mathrm{~h}$ for a hybrid made with $75 \mathrm{wt} \%$ inorganic with pTMSPMA at $2.5 \mathrm{kDa}$, to 1 minute for PTMSPMA with molecular weight of $30 \mathrm{kDa}$ without any TEOS. A new mechanism of gelation was proposed based on the different morphologies derived by AC-AFM observations. We established that the volumetric density of bridging oxygen bonds is an important parameter in structure/property relationships in $\mathrm{SiO}_{2}$ hybrids and developed a method for determining it from solid state NMR data. The variation in the elasticity of $\mathrm{PTMSPMA} / \mathrm{SiO}_{2}$ hybrids originated from pTMSPMA acting as a molecular spacer, thus decreasing the volumetric density of bridging oxygen bonds as the inorganic to organic ratio decreased.
\end{abstract}

\section{Introduction}

Sol-gel hybrids are a class of material with inorganic and organic co-networks that are indistinguishable above the nanoscale. In class II hybrids the polymer can covalently bond to the silica network during the sol-gel process. ${ }^{1}$ This intricate relationship between the organic and inorganic network leads to the synthesis of materials where the physical properties can

\footnotetext{
${ }^{a}$ Department of Materials Imperial College London, SW7 2AZ, London, UK.

E-mail: julian.r.jones@imperial.ac.uk

${ }^{b}$ Department of Physics University of Warwick, CV4 7AL, Coventry, UK.

E-mail: j.v.hanna@warwick.ac.uk

${ }^{c}$ Institute of Biomedical Engineering Imperial College London, SW7 2AZ, London, UK

${ }^{d}$ Department of Bioengineering Imperial College London, SW7 2AZ, London, UK

$\dagger$ Electronic supplementary information (ESI) available. See DOI: 10.1039/ c5cp04656d

\# Deceased.
}

exceed those of the separate compounds alone or the equivalent conventional composite. ${ }^{2}$ Establishing the relationship between the structure of silica hybrids and their mechanical properties is challenging as their failure mode can vary from that of a brittle glass to that of an elastomeric polymer. ${ }^{3-5}$ Therefore it is critical to fully understand the atomic scale and nanostructure before they can be related to the mechanical properties. The organic component of silica based class II hybrids can be classified into three main subcategories: (i) non-polymeric organo-modified silicate precursors, e.g. (3-aminopropyl)triethoxysilane, or (3-glycidoxypropyl)methyldiethoxysilane; ${ }^{6-8}$ (ii) bridged polymers (polyether, polyester, polysiloxane, etc.), where each end of the polymer can be functionalised with organo-silicate cross linkers; ${ }^{3,9,10}$ and (iii) polymers containing pending alkoxysilane groups that allow covalent coupling. ${ }^{2,11-13}$ These pending groups can be a result of functionalisation by organo-silicates molecules or by including monomeric units such as 3-(trimethoxysilyl)propyl methacrylate (TMSPMA) in radical polymerisations. ${ }^{14-16}$ The latter has the benefit of allowing a 
better integration of alkoxysilane precursor as a part of the polymer structure as post-functionalization has been shown to be sensitive to the polymer used and experimental conditions. ${ }^{17,18}$ However, little is known on the influence of the chemistry of methacrylate containing alkoxysilane polymers on the sol-gel process, especially the effect of varying the cross-linking density. Cross-linking density can be controlled by the relative concentration of alkoxysilane radical monomer to the other monomer units within the radical polymerisation. Most of the reports focusing on such materials used free radical polymerisation. Here, the aim was to use TMSPMA based polymers as model polymers for class II hybrid synthesis and to develop analytical methods for characterisation of the submicron structure of the hybrids. The new analysis methods will achieve a better understanding of how the physical properties of class II hybrids are influenced by the presence of high cross-linking density polymers and could be applied to other hybrid systems. Homopolymers of TMSPMA were used as model polymer which gives a cross-linking density of $100 \%$. Until now, structural studies on hybrids synthesised with polymethacrylate were carried out with polymers having a cross-linking density no greater than $20 \%$. For instance, Landry and Coltrain showed by small angle X-ray scattering (SAXS) and dynamic mechanical analysis (DMA) that when methyl methacrylate is copolymerised with TMSPMA and added to hydrolysed TEOS, phase separation did not occur and the gelation mechanism was altered, compared to the synthesis of pure inorganic glass. ${ }^{19-21}$ Ravarian et al. reported a significant acceleration in gelation with the addition of similar polymers into the hydrolysed inorganic sol. ${ }^{22}$ Here, the effect of molecular weight $\left(M_{\mathrm{n}}\right)$ and inorganic to organic ratio, using tetraethyl orthosilicate (TEOS) as an inorganic source, on the sol-gel process were investigated.
The morphology of the hybrids and the resulting effect on the mechanical properties were studied and compared to the current assumptions and experimental models present in the literature.

\section{Results and discussion}

\subsection{Observations on the synthesis}

Poly(3-(trimethoxysilyl)propyl methacrylate) (pTMSPMA) was chosen as a model for the organic source (Fig. 1a). Every repeating unit of the polymer has an alkoxy-silane moiety, which can potentially covalently bond to a conventional tetrasilicate glass precursor. Hence, pTMSPMA has a potential crosslinking density (the ability of a polymer to interface with the silica matrix) of $100 \%$. The effect of pTMSPMA molecular weight and its relative concentration to the TEOS were investigated. pTMSPMA was synthesised with $M_{\mathrm{n}}$ ranging from 2.5 to $30 \mathrm{kDa}$ via regulated-free radical polymerisation using thioglycerol as a chain transfer agent (Table 1 and Fig. 1a). ${ }^{16,23}$ The hydrodynamic radius of the pTMSPMA increased as the molecular weight increased. However, it was larger than poly(methyl methacrylate) (pMMA) for a given molecular weight, explaining the larger values obtained by GPC calculated against pMMA calibrants. ${ }^{24}$ In addition, due to the high steric hindrance of the alkoxy-silane moiety, pTMSPMA exhibited a high syndiotacticity as shown by the ratio of the ${ }^{1} \mathrm{H}$ NMR peak area of the atactic $\left(\delta_{\mathrm{rm}} \approx 1.02 \mathrm{ppm}\right)$ and syndiotactic $\left(\delta_{\mathrm{rr}} \approx 0.85 \mathrm{ppm}\right)$ methyl group on the back-bone (Table $1,{ }^{1} \mathrm{H}$ NMR spectra available in $\mathrm{S} 2$, ESI $\dagger) .{ }^{15}$ This implies that pTMSPMA has a high axial symmetry, where the pending groups have alternating positions along the
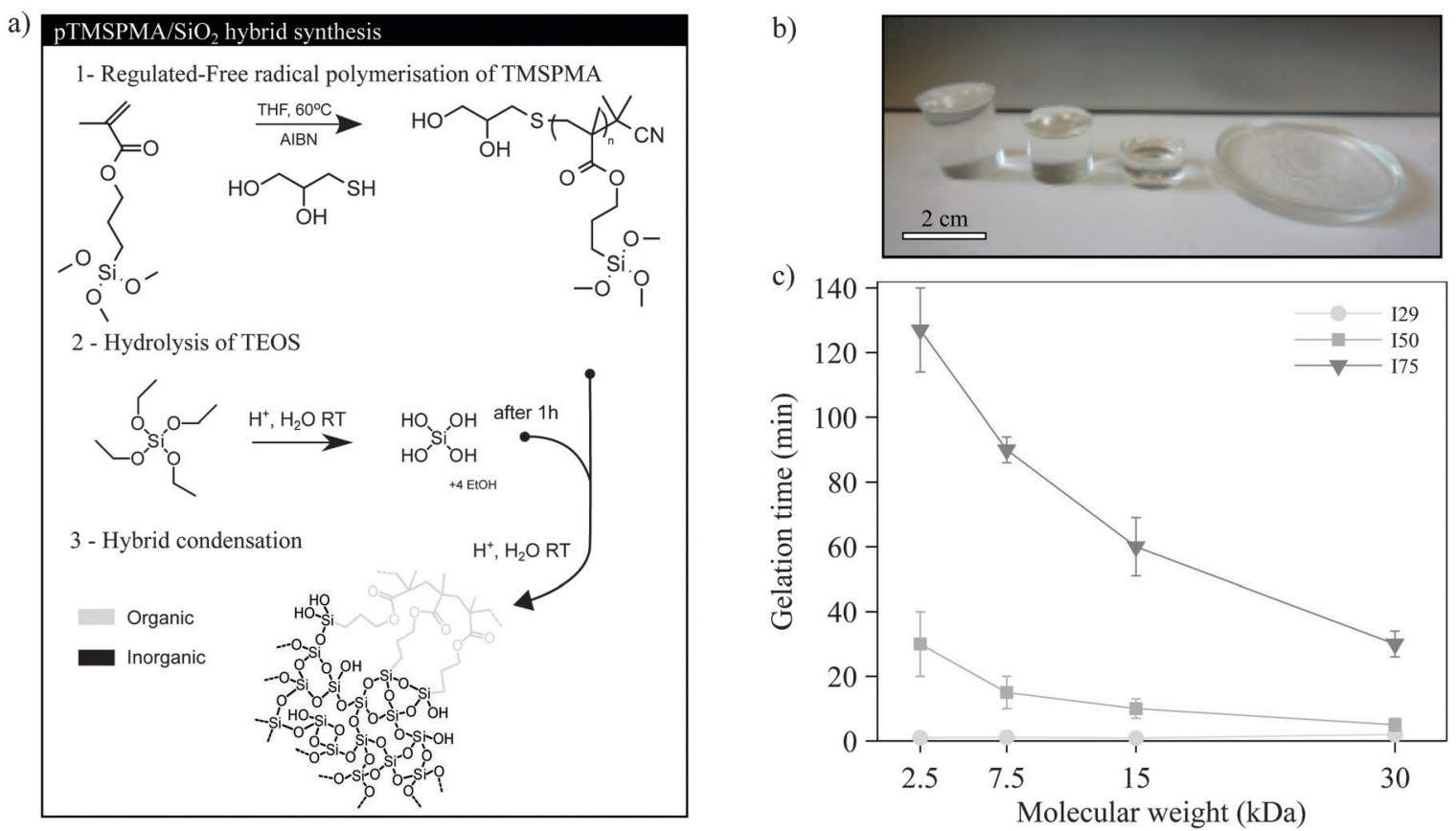

Fig. 1 (a) Schematic representing the free radical polymerisation of TMSPMA and the hybrid synthesis (b) photograph of pTMSPMA/SiO 2 hybrids after drying (c) time taken by the different sols to gel as a function of the molecular weight of pTMSPMA. Standard deviations were calculated on the basis of 3 repeats. 
Table 1 Summary of the poly(3-(trimethoxysilyl)propyl methacrylate) (pTMSPMA) characterization synthesised by regulated free radical polymerisation using thioglycerol as a chain transfer agent

\begin{tabular}{lllll}
\hline$M_{\mathrm{n}, \text { Targeted }}{ }^{a}$ & $M_{\mathrm{n}, \mathrm{GPC}^{b}}{ }^{b}$ & $\mathrm{PDI}^{b}$ & $R_{\mathrm{h}}{ }^{c}(\mathrm{~nm})$ & $\int \delta_{\mathrm{rr}} / \int \delta_{\mathrm{rm}}{ }^{d}$ \\
\hline 30000 & 33059 & 3.86 & 5.05 & $1.81 / 1$ \\
15000 & 20138 & 3.28 & 3.25 & $1.70 / 1$ \\
7500 & 11001 & 2.24 & 2.09 & $1.63 / 1$ \\
2500 & 3612 & 2.02 & 1.16 & $1.49 / 1$
\end{tabular}

${ }^{a}$ Based on the ratio of TMSPMA to thioglycerol, given in $\mathrm{g} \mathrm{mol}^{-1}$. ${ }^{b}$ Obtained by SEC relative to PMMA standards, given in $\mathrm{g} \mathrm{mol}^{-1}$. ${ }^{c}$ Obtained from dynamic light scattering in THF. ${ }^{d}$ Tacticity, obtained from ${ }^{1} \mathrm{H}$ NMR spectra, rr represent the syndiotactic part of pTMSPMA where rm represents the atactic fraction. Chromatographs and spectra are given in the S1 and S2 (ESI).

chain. No hydrolysis occurred during the polymerisation nor after purification (there was no alteration the integration of $\mathrm{Si}-\mathrm{OCH}_{3}, \delta \approx 3.58 \mathrm{ppm}$, relative to the propyl chain, $\delta \approx 3.90 \mathrm{ppm}$ ). It is important that the polymerisation reaction does not trigger any hydrolysis or condensation of the alkoxy-silane moiety of TMSPMA if a true class II inorganic-organic hybrid is to be synthesised as defined by Novak. ${ }^{1}$

Crack-free silica class II organic-inorganic hybrids were synthesised using the acid-catalysed sol-gel process, mixing hydrolysed tetraethoxyorthosilicate (TEOS) and pTMSPMA dissolved in ethanol (Fig. 1b). To focus on the effect of the polymer content and $M_{\mathrm{n}}$, hybrids or pure silica gel were prepared at the same $\mathrm{pH}$ (acidic sol-gel process $\mathrm{pH} \approx 1$ ) with the same amount of co-solvent. Several studies have shown that these two parameters have an effect on pure silica condensation, intrinsic porosity and in turn the final density. ${ }^{25,26}$ Hybrids with different silica weight percentage were produced: $29 \mathrm{wt} \%$ (hybrids made only from pTMSPMA), $50 \mathrm{wt} \%, 75 \mathrm{wt} \%$ and $100 \mathrm{wt} \%$ (pure silica gel), termed I29, I50, I75 and I100 respectively. The accuracy of inorganic to organic ratios were confirmed by thermogravimetry (TGA) and found to be within $2.5 \%$ of their target, regardless of the composition (see S3, ESI $\dagger$ ).

After 1 hour of hydrolysis of TEOS, the purified polymer was added to the solution (Fig. 1a). The addition of pTMSPMA had a noticeable effect on the gelation time as shown in Fig. 1c. ${ }^{27}$ I100 gelled within 3 days, which was consistent with literature with regards to the synthesis parameter used ( $R$ ratio and acid concentration). ${ }^{25}$ However, when pTMSPMA was introduced, gelation time decreased from two hours for I75/2.5 kDa down to one minute for I29/30 kDa. The general trend was: (i) at a fixed inorganic to organic ratio the gelation time decreased with an increase in $M_{\mathrm{n}}$ of the polymer (ii) at a fixed $M_{\mathrm{n}}$ the gelation time increased as the inorganic to organic ratio increased. A decrease in gelation time has been reported when methacrylate polymers synthesised with TMSPMA were used. ${ }^{19,22}$ In those studies, methyl methacrylate was co-polymerised with TMSPMA to reach a cross linking density of approximately $20 \%$. At a comparable $M_{\mathrm{n}}$ and inorganic to organic ratio, the gelation appeared to be 5 times slower compared to that reported here. Thus, it can be assumed that the cross-linking density of methacrylate polymer as well as the nature of its functional group (co-monomer) has a strong influence on the mechanism of gelation (i.e. polymerisation of the inorganic phase).

\subsection{Morphology and gelation mechanism}

In order to get a better understanding of the gelation mechanism, the morphology of the silica class II hybrid was analysed using acoustic atomic force microscopy (AC-AFM, also called tapping mode), by looking at the distribution of the cantilever phase. Shifts in phase oscillation of the cantilever depend on the energy dissipated at the tip-sample region. The energy dissipation is usually characterised as a local change in stiffness, viscoelasticity or long-range interfacial interactions at the nanoscale. ${ }^{28-30}$ Fig. $2 \mathrm{a}$ shows the variation in the phase accumulative distribution (also called Abbott-Firestone curve), averaged over a region of $1 \mu \mathrm{m}$ by $1 \mu \mathrm{m}$ at different inorganic to organic ratios. The phase mappings encompassing these accumulated distributions (from -30 to $45^{\circ}$ ) are given in Fig. S4 (ESI $\dagger$ ). As the inorganic content increased, the mode of the angle distribution decreased from $26.56^{\circ}$ for $\mathrm{I} 29$ down to $20.18^{\circ}$ for I100. In addition, at I29 and I100, the distributions were relatively narrow with a full width at half maximum (FWHM) of $\approx 10^{\circ}$, whereas when the two precursors were mixed together (I50 and I75) an increase of the FWHM of at least $5^{\circ}$ was observed. The relatively higher phase distribution observed for I29 suggests that the silica matrix induced by pTMSPMA allowed a greater dissipation of energy at the AFM tip-sample region, due to the reduced stiffness of the PTMSPMA compared to $100 \% \mathrm{SiO}_{2}$. Therefore, in order to localise the areas of high energy dissipation, thus the polymer rich regions, the phase of the hybrids at different inorganic to organic ratio was mapped only from 25 to $35^{\circ}$ (high phase), as shown in Fig. 2b. It is important to note here that when displayed at a full scale $\left[-30^{\circ}\right.$; $45^{\circ}$ ], the phase images did not show any significant contrast (see S4, $\mathrm{ESI} \dagger$ ). However, over this restricted phase range, discontinuities were observed, characterised by isolated high phase regions not exceeding $50 \mathrm{~nm}$, regardless of composition. A homogenous mosaic composed of $\approx 18 \mathrm{~nm}$ non-spherical rough domains was observed for I29 with a slight isotropic effect due to a phase drift caused by an increase in the surface charge originating from the polymer backbone (electrostatic effect) which was not seen in higher inorganic to organic ratios. These rough domains were larger for I50 (77 nm) and smaller for I75 $(11 \mathrm{~nm})$. For I100, small regions of less than $5 \mathrm{~nm}$ homogeneously distributed across the map were observed, representing $2.78 \%$ of the projected area. These observations were not affected by the $M_{\mathrm{n}}$ of pTMSPMA, except at I50, for which average size of the high phase regions linearly increased $\left(R^{2}=0.98\right)$ with the molecular weight, starting from 40.3 for $2.5 \mathrm{kDa}$ pTMSPMA up to $77 \mathrm{~nm}$ for $30 \mathrm{kDa}$ pTMSPMA (see S5, ESI $\dagger$ ).

Fig. 2c shows the corresponding topography of the different samples described above. The fracture surfaces of the hybrids were found to be smooth with a average roughness of $7.76 \pm$ $1.8 \mathrm{~nm}$ (no statistical differences between the different samples). This low roughness also validated that the changes in phase were only due to local change in chemistry of the material and not due to significant change in topography.

The following gelation mechanisms are proposed for pTMSPMA/ $\mathrm{SiO}_{2}$ class II hybrids, depending of the relative concentration of 
(a)
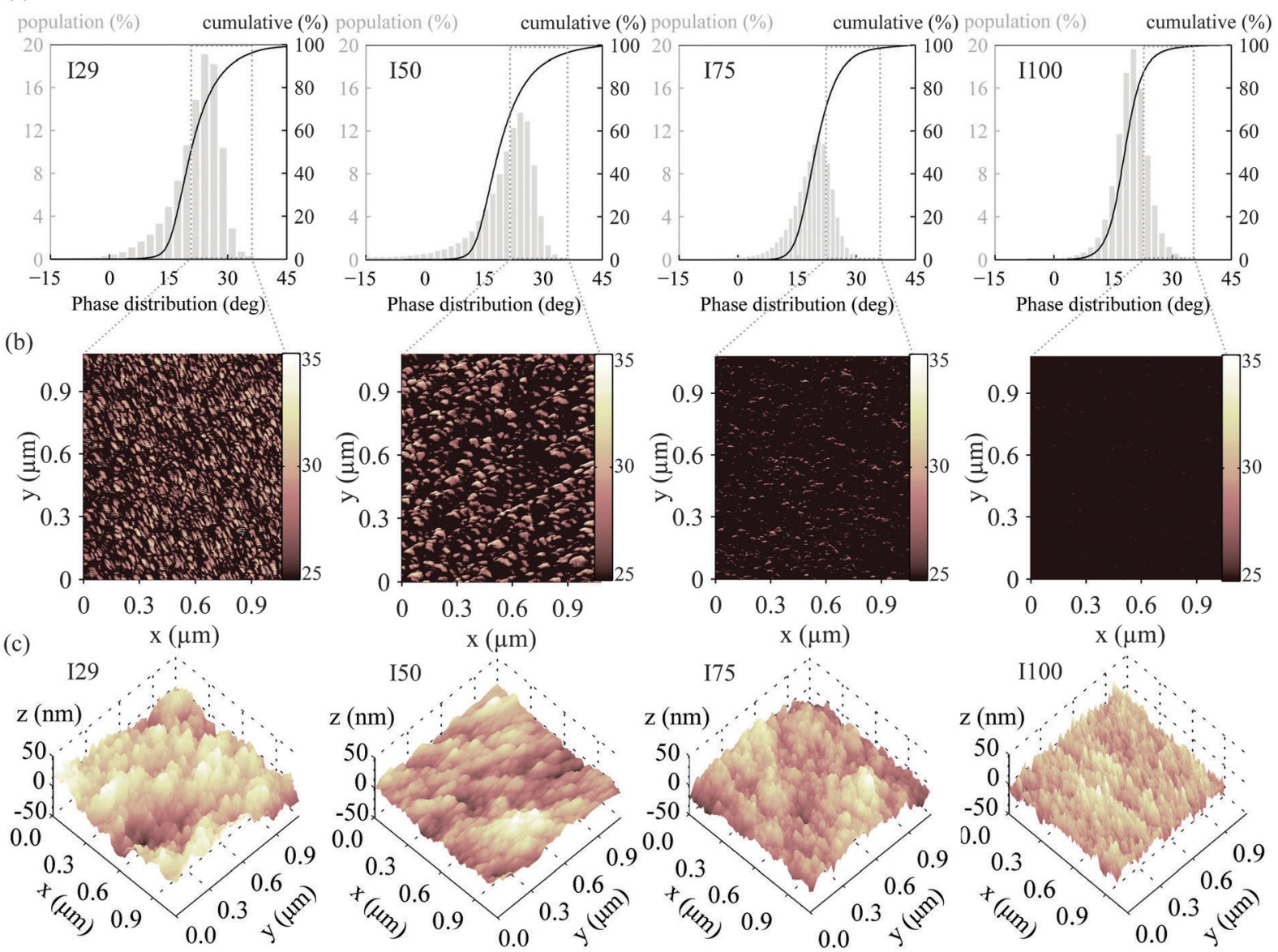

Fig. 2 Acoustic atomic force microscopy conducted on PTMSPMA $/ \mathrm{SiO}_{2}$ hybrids with pTMSPMA at $30 \mathrm{kDa}$ at different inorganic to organic ratio. (a) Represents the average phase distribution over an area of $1 \mu \mathrm{m}$ by $1 \mu \mathrm{m}$, (b) phase mapping from 25 to $35^{\circ}$, (c) the corresponding topography.

the polymer to TEOS. Upon the addition of the polymer, TEOS has condensed to formed dimers or cage-like silica particles ( $\leq 1 \AA)$, which were at least an order of magnitude smaller in diameter than PTMSPMA, $1.16 \mathrm{~nm}$ for PTMSPMA at $2.5 \mathrm{kDa}$ (see Table 1). ${ }^{26}$ Thus, at high concentration (I29 and I50), due to the larger size of the polymer particles, pTMSPMA formed a opened polymeric mesh by self-condensation within which (at I50) the hydrolysed tetrasilicate precursors condensed. The size of the mesh was directly impacted by $M_{\mathrm{n}}$ of pTMSPMA, as shown in the AC-AFM phase mapping (S5, ESI $\dagger$ ). At I75, the concentration of the polymer was not sufficient to form a polymer mesh; therefore, we assume that PTMSPMA catalysed the formation of secondary particles, which are the product of the intercondensation of silica branched polymer (primary particles) that forms through the reaction limited cluster-cluster aggregation of the hydrolysed tetrasilicate precursor. ${ }^{25,26}$

\subsection{Mechanical properties by depth-sensing indentation}

Nanoindentation was used to characterise the mechanical properties of the hybrids. Analysis of nanoindentation data depends on the mode of deformation of the material. ${ }^{31}$ In other methacrylate based hybrids, Mammeri et al. found that the addition of poly $\left(\mathrm{MMA}_{95}-\mathrm{co}-\mathrm{TMSPMA}_{5}\right)$ to the silica matrix led to viscoelasticity. ${ }^{32-34}$ Therefore, we hypothesised that the conventional Oliver and Pharr method to extract the Young's modulus, could not be used here, as it assumes deformation to be elastic-plastic. ${ }^{35}$ Here, the reduced Young's modulus, hardness and the quadratic viscosity coefficient were extracted from the load-displacement curve using the Viscous-ElasticPlastic (VEP) model, as formulated by Oyen and Cook. ${ }^{36}$ In this model, the displacement of an indenter is the sum of a plastic $h_{\mathrm{p}}$, a elastic $h_{\mathrm{e}}$ and a viscous $h_{\mathrm{v}}$ elements placed in series as described by the Maxwell model. ${ }^{37}$

$$
h=h_{\mathrm{v}}+h_{\mathrm{e}}+h_{\mathrm{p}}
$$

Due to the geometrical profile of the Berkovick indenter, the load-displacement relationship of each element (a spring for the elastic response, a dashpot for the viscous response and a friction block for the plastic response) are expressed quadratically: ${ }^{36}$

$$
\begin{aligned}
\frac{\mathrm{d} h}{\mathrm{~d} t} & =\frac{\mathrm{d} h_{\mathrm{v}}}{\mathrm{d} t}+\frac{\mathrm{d} h_{\mathrm{e}}}{\mathrm{d} t}+\frac{h_{\mathrm{p}}}{\mathrm{d} t} \\
\frac{\mathrm{d} h}{\mathrm{~d} t} & =\sqrt{\frac{F}{\alpha_{3} \eta_{\mathrm{Q}}}}+\frac{1}{\sqrt{F}} \frac{\mathrm{d} F}{\mathrm{~d} t} \frac{1}{2 \sqrt{\alpha_{2} E_{\mathrm{r}}}}+\frac{1}{\sqrt{F}} \frac{\mathrm{d} F}{\mathrm{~d} t} \frac{1}{2 \sqrt{\alpha_{1} H}}
\end{aligned}
$$



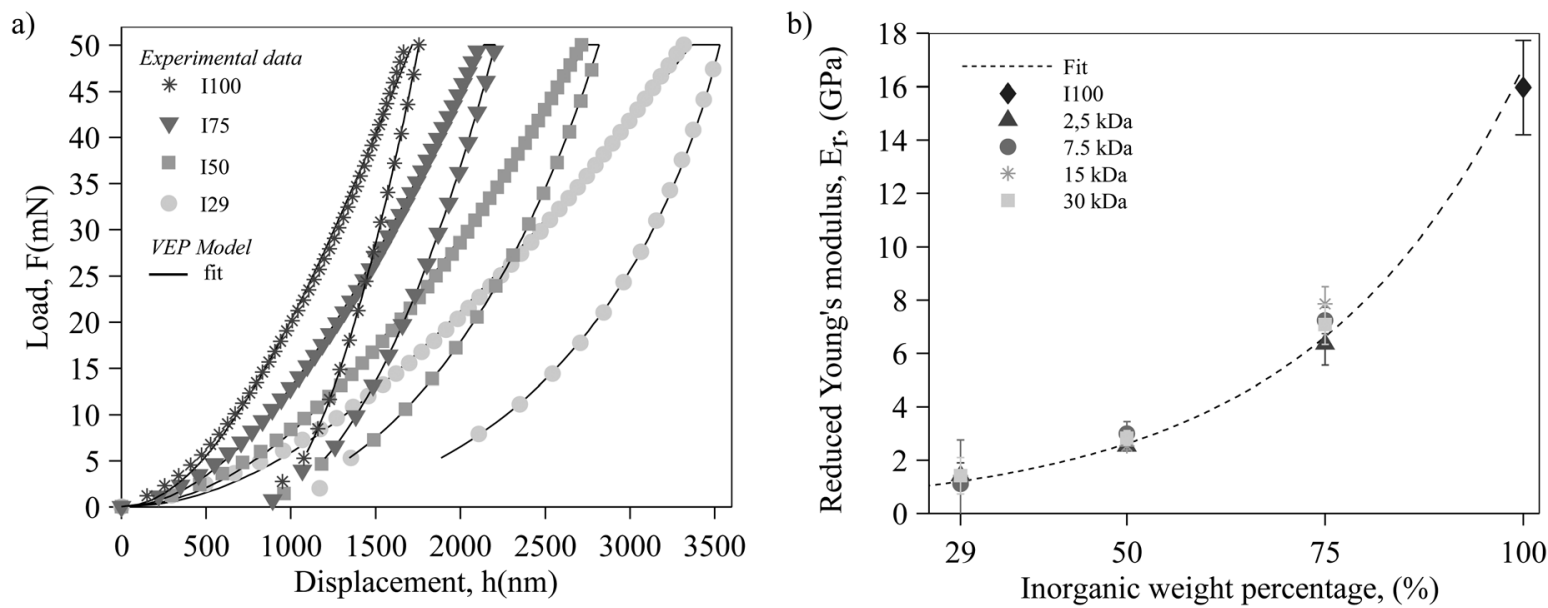

Fig. 3 (a) Experimental and predicted load-displacement for the methacrylate/silica class II hybrids synthesised with 15 kDa pTMSPMA at different inorganic to organic ratios and (b) reduced Young's modulus as a function of the inorganic-organic weight percentage. The Young's modulus, $E$, is related to the reduced Young's modulus by $E_{\mathrm{r}}=\frac{E}{1-\nu^{2}}$, where $\nu$ is the Poisson's ratio.

where $F$ is the load applied by the indenter, $E_{\mathrm{r}}$ the reduced Young's modulus, $H$ the hardness of the materials, $\alpha_{3} \eta_{\mathrm{Q}}$ is the quadratic viscosity, $\alpha_{1}$ and $\alpha_{2}$ are dimensionless geometry constants function of the included angle of the sharp indenter. A schematic representation of the Maxwell model and the expression of the geometrical parameters are given in ESI $\dagger$ (S6).

Fig. 3a shows the experimental and predicted loaddisplacement curves obtained for the pTMSPMA $/ \mathrm{SiO}_{2}$ hybrids. Table 2 summarises the corresponding values extracted from the VEP model from hybrids synthesised with pTMSPMA of $M_{\mathrm{n}}$ of $15 \mathrm{kDa}$ pTMSPMA (full table in T1, ESI $\dagger$ ). All samples underwent crack-free deformation under loading as shown by the continuous displacements of the indenter under a constant load rate of $5 \mathrm{mN} \mathrm{s}^{-1} \cdot 38,39$ As the inorganic-organic ratio increased the displacement at the maximum load decreased from $3.32 \mu \mathrm{m}$ (for I29) to $1.68 \mu \mathrm{m}$ (for I100) showing an increase in stiffness as the inorganic increased. Likewise, the reduced Young's modulus and the hardness increased as the organic content decreased (Table 2 and Fig. 3b). The mechanical properties measured had a low deviation from their mean values, showing the homogeneity in composition of the hybrid. The displacement of the indenter at the maximum load (dwell of $20 \mathrm{~s}$ ) increased as the organic content increased, from $77 \mathrm{~nm}$

Table 2 Reduced Young's modulus, $E_{r}$, hardness, $H$, and viscoelastic factor, $\alpha_{3} \eta_{Q}$, extracted from nanoindentation data using the ViscousElastic-Plastic model at different inorganic to organic ratios. PTMSPMA/ $\mathrm{SiO}_{2}$ hybrids synthesised with pTMSPMA $M_{\mathrm{n}}$ of $15 \mathrm{kDa}$. Mean and standard deviation are given on a basis of 50 measurements. The Young's modulus, $E$, is related to the reduced Young's modulus by $E_{\mathrm{r}}=\frac{E}{1-\nu^{2}}$, where $\nu$ is the Poisson's ratio

\begin{tabular}{lrlr}
\hline Hybrid & \multicolumn{1}{l}{$E(\mathrm{GPa})$} & $H(\mathrm{GPa})$ & \multicolumn{1}{c}{$\alpha_{3} \eta_{\mathrm{Q}}\left(10^{12} \mathrm{~Pa} \mathrm{~s}^{2}\right)$} \\
\hline I29 & $1.41 \pm 0.23$ & $0.25 \pm 0.03$ & $8.57 \pm 1.33$ \\
I50 & $2.53 \pm 0.32$ & $0.45 \pm 0.03$ & $25.19 \pm 2.60$ \\
I75 & $7.35 \pm 0.98$ & $1.32 \pm 0.05$ & $40.89 \pm 1.65$ \\
I100 & $15.96 \pm 0.73$ & $3.40 \pm 0.01$ & $40.29 \pm 1.25$
\end{tabular}

(for I100) to $213 \mathrm{~nm}$ (for I29), corresponding to an increase in the viscoelastic response. In addition, the VEP model allowed a quantitative measurement of the viscosity with the extraction of a quadratic viscosity factor, $\alpha_{3} \eta_{\mathrm{Q}}$, which decreased as the organic content increased near or above $50 \mathrm{wt} \%$. According to the gelation mechanism proposed earlier, this sudden decrease corresponded to the transition between pTMSPMA being responsible for the gelation of the sol, by the formation of a polymeric mesh (I29 and I50), to acting as a catalyst in the formation of silica secondary particles. ${ }^{26}$ Interestingly, $\alpha_{3} \eta_{\mathrm{Q}}$ was not influenced by the $M_{\mathrm{n}}$ of the polymer. In fact, none of the mechanical quantities extracted from the VEP model were influenced by $M_{\mathrm{n}}$. The scale of the indent was at least one order of magnitude larger than the characteristic size of the polymer mesh observed by AC-AFM (see Fig. 2), it is therefore likely that a macroscopic average effect on the mechanical properties was observed where PTMSPMA $M_{\mathrm{n}}$ did not have any significant effect.

Mammeri et al. made similar observations on hybrid thin films synthesised with poly(MMA $\mathrm{MM}_{95}-\mathrm{co}$-TMSPMA $\left.{ }_{5}\right) \cdot{ }^{32-34}$ As their inorganic content increased, $E_{\mathrm{r}}$ increased, ranging from 4.10 to 17.5 GPa. However, at a given inorganic-organic ratio the $E_{\mathrm{r}}$ reported was greater than the values reported here. The $E_{\mathrm{r}}$ in the thin films could have been an overestimate due to the empirical method of subtraction of the mechanical influence of the film substrate. ${ }^{40,41}$ Wei et al. reported lower values of the Young's modulus to the thin film performing compression strength test on monoliths of similar compositions. ${ }^{42}$ They also showed that the $M_{\mathrm{n}}$ of the polymer had a minimal effect on the mechanical properties of the hybrids with respect of their experimental conditions.

\subsection{Structure-property relationships}

Relationship between the structure and the mechanical properties of the pTMSPMA $/ \mathrm{SiO}_{2}$ hybrids were investigated using solid state magic-angle spinning nuclear magnetic resonance (MAS-NMR). 
a)

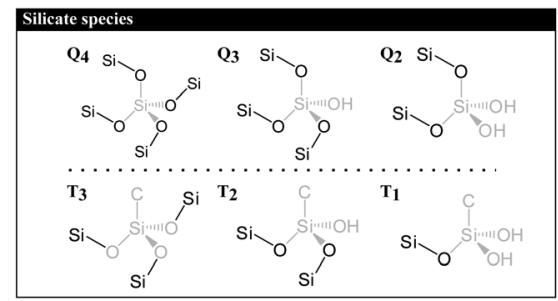

b)

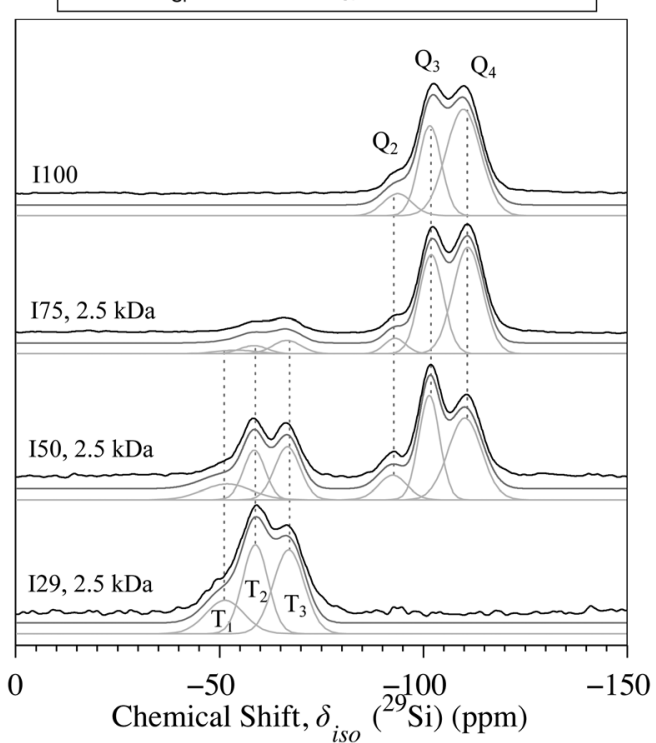

Fig. 4 (a) Representation of the different silica species seen in the (b) one pulse ${ }^{29} \mathrm{Si}$ MAS NMR spectra of hybrids synthesised with PTMSPMA at $2.5 \mathrm{kDa}$ at different inorganic to organic ratio.

${ }^{29} \mathrm{Si}$ MAS-NMR was used to quantify the number of bridging oxygen, $n$, that a silicon atom can have with other surrounding silica tetrahedra. Thus, two types of bridging oxygen species were detected; from silica network formed through the condensation of PTMSPMA $\left(\mathrm{T}^{n}\right.$, centred around $\left.-60 \delta_{\mathrm{T}^{n}}\right)$ and from the TEOS $\left(\mathrm{Q}^{n}\right.$, centred around $\left.-110 \delta_{\mathrm{Q}^{n}}\right)$. A structural representation of the different species is given in Fig. 4a. Fig. 4b shows the deconvoluted single pulse ${ }^{29} \mathrm{Si}$ MAS NMR spectra of the hybrids synthesised with pTMSPMA with $M_{\mathrm{n}}$ of $30 \mathrm{kDa}$ and $2.5 \mathrm{kDa}$ pTMSPMA as well as I100. The proportion of $\mathrm{T}^{n}$ and $\mathrm{Q}^{n}$ species are given in

Table 3 Detail of the chemical shifts and proportions of the different silica species, $T$ and $Q$, present in the PTMSPMA/SiO 2 hybrids from the deconvolution of the once-pulse ${ }^{29} \mathrm{Si}$ MAS-NMR spectra. $d_{\mathrm{C}, \mathrm{Q}}$ and $d_{\mathrm{C}, \mathrm{T}}$ represent the degree of condensation of corresponding species and $D_{c, \text { total }}$ the total degree of condensation. $Q^{n}$ are Si tetrahedral units with $n$ the number of bridging oxygen bonds. $\mathrm{T}^{n}$ are $\mathrm{Si}$ units with a $\mathrm{Si}-\mathrm{C}$ bond and $n$ bridging oxygen bonds

\section{Proportions (\%)}

\begin{tabular}{lcrrrrrrrrr} 
Hybrid, $M_{\mathrm{n}}$ & $\mathrm{T}^{1}$ & $\mathrm{~T}^{2}$ & $\mathrm{~T}^{3}$ & $\mathrm{Q}^{2}$ & $\mathrm{Q}^{3}$ & $\mathrm{Q}^{4}$ & \multicolumn{2}{c}{$d_{\mathrm{c}, \mathrm{T}}(\%)$} & $d_{\mathrm{c}, \mathrm{Q}}(\%)$ & $D_{\mathrm{c}, \text { total }}(\%)$ \\
\hline $\mathrm{I} 100$ & - & - & - & 10.0 & 32.1 & 57.9 & 0 & 87.0 & 87.0 \\
$\mathrm{I} 29,30 \mathrm{kDa}$ & 25.1 & 42.9 & 32.0 & - & - & - & 69.0 & 0 & 69.0 \\
$\mathrm{I} 50,30 \mathrm{kDa}$ & 5.52 & 11.0 & 14.4 & 5.6 & 27.9 & 35.6 & 76.2 & 85.8 & 82.9 \\
$\mathrm{I} 75,30 \mathrm{kDa}$ & 1.2 & 4.0 & 2.6 & 6.8 & 35.8 & 49.7 & 72.9 & 86.6 & 85.6 \\
$\mathrm{I} 29,2.5 \mathrm{kDa}$ & 20.8 & 37.0 & 42.2 & - & - & - & 73.8 & 0 & 73.8 \\
$\mathrm{I} 50,2.5 \mathrm{kDa}$ & 8.6 & 12.3 & 15.3 & 7.8 & 24.7 & 31.2 & 72.8 & 84.1 & 80.1 \\
$\mathrm{I} 75,2.5 \mathrm{kDa}$ & 1.7 & 3.4 & 5.8 & 5.1 & 36.1 & 48.0 & 79.2 & 87.0 & 86.2
\end{tabular}

Table 3. Despite a decrease in the inorganic content, the chemical shifts of the different $\mathrm{Q}$ species remained relatively unchanged within a average deviation of $0.26 \delta$. $\mathrm{Q}^{4}$ units represent the fully condensed part of the silica network. According to Mauri et al., the chemical shift $\delta_{\mathrm{Q}^{4}}$ could be linearly correlated to the $\mathrm{Si}-\mathrm{O}-\mathrm{Si}$ bond angle in vitreous silica by the following equation when $\delta_{\mathrm{Q}^{4}}$ $<120$ ppm: ${ }^{43}$

$$
\delta_{\mathrm{Q}^{4}}(\theta)=-93.12+8.66 \cos (\theta)-22.27 \cos (2 \theta)
$$

where $\theta$ is the dihedral angle between two condensed silicon atoms. Thus, according to this equation, the $\mathrm{Si}-\mathrm{O}-\mathrm{Si}$ bond distribution was centred around $147.4^{\circ}$ with a variation in mode of $1.2^{\circ}$, typical of a relaxed network, which has not been heat treated. Therefore, this suggests that pTMSPMA had no effect on the silica network formed from TEOS.

From the percentages of $\mathrm{T}$ and $\mathrm{Q}$ species obtained from deconvoluting the spectra, the average degree of condensation of the silica network was calculated as follows: the partial degree of condensation of the T and Q species, termed $d_{\mathrm{c}, \mathrm{T}}$ and $d_{\mathrm{c}, \mathrm{Q}}$ as well as the total degree of condensation $D_{\mathrm{c}, \text { total }}$ were obtained from the respective area under the curve (A) of each silicate species $\left(\mathrm{T}^{n}\right.$ or $\left.\mathrm{Q}^{n}\right)$ as shown in eqn (4):

$$
\begin{aligned}
d_{\mathrm{c}, \mathrm{X}} & =\frac{\sum_{1}^{N} \frac{n \times A_{\mathrm{X}^{n}}}{N}}{\sum_{1}^{N} A_{\mathrm{X}^{n}}} \times 100 ; \\
D_{\mathrm{c}, \text { total }} & =\frac{\sum_{1}^{N_{\mathrm{T}}} \frac{n \times A_{\mathrm{T}^{n}}}{N_{\mathrm{T}}}+\sum_{1}^{N_{\mathrm{Q}}} \frac{n \times A_{\mathrm{Q}^{n}}}{N_{\mathrm{Q}}}}{\sum_{0}^{N} A_{\mathrm{X}^{n}}} \times 100
\end{aligned}
$$

where $\mathrm{X}=\mathrm{T}$ or $\mathrm{Q}$ for their respective partial degree of condensation and $\mathrm{X}=\mathrm{T}$ and $\mathrm{Q}$ for the total degree of condensation. The proportion of each silica species and the different degree of condensations obtained for the pTMSPMA/SiO $\mathrm{S}_{2}$ hybrids are given in Table 3. It is noteworthy to mention that each hybrid contained $\mathrm{Q}_{2}, \mathrm{Q}_{3}$ and $\mathrm{Q}_{4}$, and $\mathrm{T}_{1}, \mathrm{~T}_{2}$ and $\mathrm{T}_{3}$, with a distribution of the $\mathrm{Q}$ species typical of gel prepared by the acidic route $(\mathrm{pH}<2) \cdot{ }^{25,44,45}$ The total degree of condensation $D_{\text {c,total }}$ increased with the inorganic fraction from $69 \%$ for 129 to $87 \%$ for I100. I100 did not have a $D_{\text {c,total }}$ of $100 \%$ because $\mathrm{H}^{+}$ ions act as network modifiers, leaving $\mathrm{Si}-\mathrm{OH}$ groups in the silicate structure. For I29, the fast gelation and high tacticity of PTMSPMA is likely to have caused steric hinderance of the condensation. ${ }^{46}$ The increase of $d_{\mathrm{c}, \mathrm{T}}$ with the molecular suggests that the condensation reaction for I29 is the favoured by the stereochemistry of the polymer with an increase in the $d_{\mathrm{c}, \mathrm{T}}$ as the tacticity of PTMSPMA increased. For I50 and I75, we assume that the tetrasilicate precursors co-condensed with the organo-trisilicate precursors of the polymer, causing an increase of $D_{\text {c,total }}$. This hypothesis is reinforced when looking at the partial degree of condensation of the $\mathrm{T}$ species, $d_{\mathrm{c}, \mathrm{T}}$, which also increased from $69 \%$ for I29 to a minimum of $72.8 \%$ when PTMSPMA was mixed with hydrolysed TEOS. Therefore, 
Table 4 Skeletal density $\left(\rho_{\mathrm{s}}\right)$ of the $\mathrm{pTMSPMA} / \mathrm{SiO}_{2}$ hybrids and the intermediate results allowing the calculation the volumetric density of bridging oxygen, $\rho_{\mathrm{v}, \mathrm{Si}-\mathrm{O}-\mathrm{Si}}$. $N_{\mathrm{A}}$ is the Avogadro's constant

\begin{tabular}{llllll}
\hline & & \multicolumn{2}{l}{$\rho_{\mathrm{v}, \mathrm{Si}-\mathrm{O}-\mathrm{Si}}\left(\mathrm{Si}-\mathrm{O}-\mathrm{Si} \mathrm{cm}{ }^{-3} N_{\mathrm{A}}{ }^{-1}\right)$} \\
\cline { 5 - 7 } Hybrid, $M_{\mathrm{n}}$ & $\rho_{\mathrm{s}}\left(\mathrm{g} \mathrm{cm}^{3}\right)$ & Polymer $_{\mathrm{c}}(\mathrm{wt} \%)$ & $\mathrm{T}$ & $\mathrm{Q}$ & Total \\
\hline $\mathrm{I} 100$ & 2.021 & 0 & 0 & 0.0292 & 0.0292 \\
$\mathrm{I} 29,30 \mathrm{kDa}$ & 1.360 & 100 & 0.0052 & 0 & 0.0052 \\
$\mathrm{I} 50,30 \mathrm{kDa}$ & 1.429 & 70.5 & 0.0043 & 0.0060 & 0.0103 \\
$\mathrm{I} 75,30 \mathrm{kDa}$ & 1.669 & 35.2 & 0.0024 & 0.0156 & 0.0180 \\
$\mathrm{I} 29,2.5 \mathrm{kDa}$ & 1.370 & 100 & 0.0056 & 0 & 0.0056 \\
$\mathrm{I} 50,2.5 \mathrm{kDa}$ & 1.426 & 70.8 & 0.0027 & 0.0059 & 0.0086 \\
$\mathrm{I} 75,2.5 \mathrm{kDa}$ & 1.601 & 35.4 & 0.0023 & 0.0141 & 0.0164 \\
\hline
\end{tabular}

${ }^{29} \mathrm{Si}$ MAS-NMR indicates that true class II hybrids were synthesised.

The degree of condensation is an important metric that has been used to correlate change in mechanical properties of hybrids as a function of the concentration or type silica precursors. ${ }^{5}$ However, the degree of condensation on its own does not account for the spatial distribution and concentration (i.e. density) of the bridging oxygen species which could lead to a false interpretation since the Young's modulus could vary as a function of the density at a fixed degree of condensation. ${ }^{47}$ Moreover, the skeletal density of the pTMSPMA/SiO ${ }_{2}$ hybrid, $\rho_{\mathrm{s}}$, was found to vary as a function of the inorganic to organic ratio (Table 4 and S8, ESI $\dagger$ ). In this paper, a new approach is given to evaluate the combination of the two effects through a new experimental metric: the volumetric
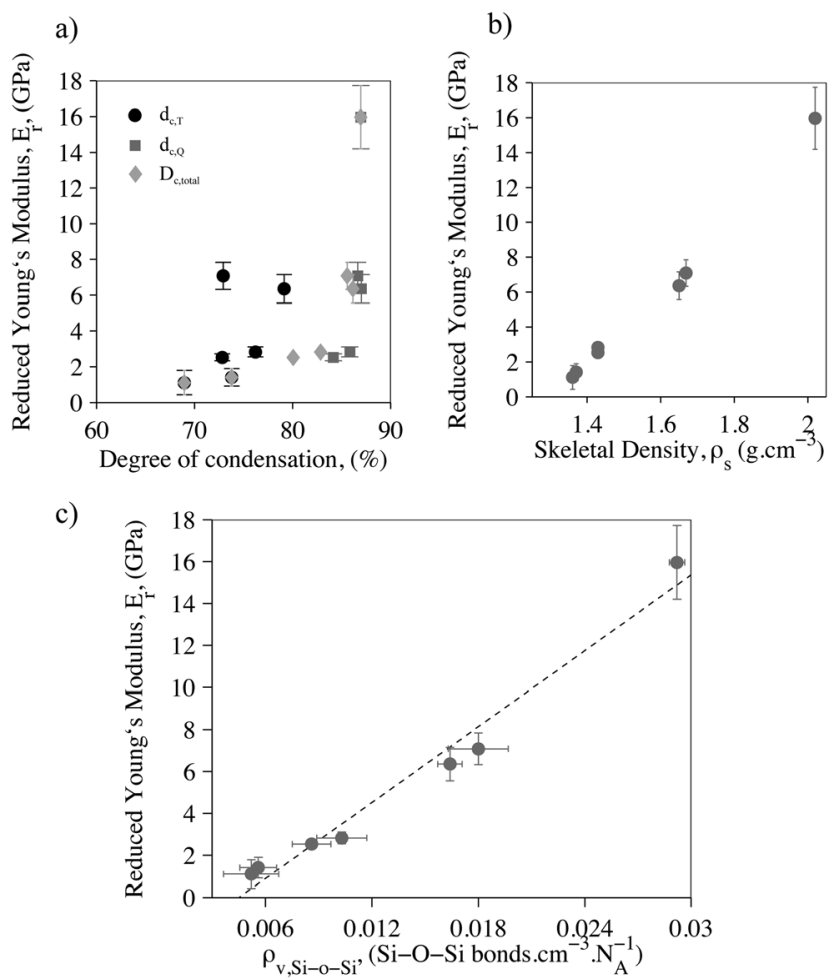

Fig. 5 Correlation between the $E_{r}$ and (a) the degree of condensation of the different silica species, (b) the skeletal density and (c) the volumetric density of bridging oxygen for $\mathrm{pTMSPMA} / \mathrm{SiO}_{2}$ hybrids. The fit was a linear regression with $R^{2}=0.97$. density of the silica bridging oxygens, $\rho_{\mathrm{v}, \mathrm{Si}-\mathrm{O}-\mathrm{Si}}$. To calculate $\rho_{\mathrm{v}, \mathrm{Si}-\mathrm{O}-\mathrm{Si}}$, first, the molar density $\left(\mathrm{mol} \mathrm{cm}^{-3}\right.$ ) of each silica domain (polymer or tetrasilicate) was extracted using their inherent molar mass and the polymer weight fraction $M_{\mathrm{r}}$ from the skeleton density (N.B. the weight fraction of the polymer is different to the inorganic-organic ratio since it takes into account the contribution of the suboxide from TMSPMA). Then, the volumetric density of $\mathrm{Si}-\mathrm{O}-\mathrm{Si}$ bonds relative to each species was estimated from their partial degree of condensation $d_{\mathrm{c}, \mathrm{T}}$ and $d_{\mathrm{c}, \mathrm{Q}}$ and the silica molar densities. Finally, the total volumetric density was given by summation of the above quantities as shown in eqn (5):

$$
\rho_{\mathrm{v}, \mathrm{Si}-\mathrm{O}-\mathrm{Si}}=\rho_{\mathrm{s}} \times M_{\mathrm{r}} \times\left(\frac{d_{\mathrm{c}, \mathrm{T}}}{M_{\mathrm{w}, \mathrm{TMSPMA}}}+\frac{1-M_{\mathrm{r}} d_{\mathrm{c}, \mathrm{Q}}}{M_{\mathrm{r}} M_{\mathrm{w}, \mathrm{SiO}_{2}}}\right)
$$

Intermediate results and $\rho_{\mathrm{v}, \mathrm{Si}-\mathrm{O}-\mathrm{Si}}$ are given in Table 4. Hence, it became clear that the initial concentration of pTMSPMA in the sol had a noticeable effect the final hybrid $\rho_{\mathrm{v}, \mathrm{Si}-\mathrm{O}-\mathrm{Si}}$, which varied from $5.2 \times 10^{-3} \mathrm{~cm}^{-3} N_{\mathrm{A}}^{-1}$ for $\mathrm{I} 29$ up to $29 \times 10^{-3} \mathrm{~cm}^{-3} N_{\mathrm{A}}^{-1}$. This suggests that methacrylate polymers with a high degree of cross-linking, such as PTMSPMA, acts as spacers in the silica matrix, and therefore lowering the density of bridging oxygens as its concentration increases in the hybrid. A linear interdependence was found to exist between $E_{\mathrm{r}}$ and $\rho_{\mathrm{v}, \mathrm{Si}-\mathrm{O}-\mathrm{Si}}$ as shown in Fig. $5 \mathrm{c}$. The reduced Young's modulus was also plotted against the different degrees of condensation and the skeletal density $\rho_{\mathrm{s}}$ as shown in Fig. $5 \mathrm{a}$ and b, respectively. This decrease in volumetric density of bridging oxygens could therefore explain the decline in the $E_{\mathrm{r}}$ when the inorganic to organic ratio decreased.

\section{Conclusion}

It is clear from the data presented here that class II silica hybrids are a unique class of material, different to conventional composites. As such, characterisation techniques must be adapted to the intrinsic nature of the relationship between the organic and inorganic phase through the development of new tools or the adaptation of existing methods, such as these developed here. A new gelation mechanism for hybrid sols with polymer of high cross-linking density was proposed based on morphology of the resulting hybrids using acoustic atomic force microscopy. Nanoindentation revealed that the mode of deformation was a function of the inorganic to organic ratio. Thus, hybrids require analytical methods that take into account these changes in properties, such as the VEP model. The volumetric density of $\mathrm{Si}-\mathrm{O}-\mathrm{Si}$ bonds is an important parameter in determining structure-property relationships and can be determined by treatment of solid state NMR data. Variation in the elasticity of the hybrids were a direct consequence of the addition of pTMSPMA, which acts as a bridging oxygen spacer, lowering $\rho_{\mathrm{v}, \mathrm{Si}-\mathrm{O}-\mathrm{Si}}$. In this class II hybrids system, control of the mechanical properties can be obtained by varying the inorganic to organic ratio while $M_{\mathrm{n}}$ had no effect. Though a better understanding of the relationship between the organic and 
inorganic components, the properties of class II hybrids could fulfil their potential of materials with highly tailorable properties.

\section{Experimental}

\subsection{Polymer and hybrid synthesis}

Synthesis of pTMSPMA. 3-(Trimethoxysilyl)propyl methacrylate (TMSPMA) was polymerised by free radical polymerisation, using AIBN as an initiator, in THF, at $60{ }^{\circ} \mathrm{C}$. The average molecular weight of the polymer was controlled by introducing thioglycerol (TG) as a chain transfer agent and varying its concentration relative to the TMSPMA. Thus, the molar ratio $R_{0}=\frac{n_{\text {chain transfer agent }}}{n_{\text {monomer }}}$ varied between $0.8 \%$ to $9.9 \%$ to give a degree of polymerisation going from 10 to 120 as detailed in the Table 5 .

The concentration of initiator was kept constant relative to the monomer concentration with a molar ratio $C_{0}=\frac{n_{\text {initiator }}}{n_{\text {monomer }}}=15 \%$. The concentration of monomer was $1 \mathrm{~mol} \mathrm{~L}^{-1}$. Before any synthesis, the glassware was dried in an oven at $60{ }^{\circ} \mathrm{C}$ for a minimum of 2 hours. In a typical synthesis, all reagents were introduced in a round bottom flask by mass with a $0.5 \mathrm{mg}$ accuracy and the flask was sealed with a silicon septa. Then, the polymerisation solution was bubbled with argon for $30 \mathrm{~min}$ to reduce the level of oxygen and left under a positive relative pressure by removing the gas inlet last. The polymerisation was started by putting the round bottom flask at $60{ }^{\circ} \mathrm{C}$ in a prewarmed oil bath. The reaction was held at $60{ }^{\circ} \mathrm{C}$ for $48 \mathrm{~h}$ under stirring (300 rpm) after which the product was purified by precipitation in $n$-hexane, 3 times, to remove all the unreacted monomers, chain transfer agents and initiators. The polymer was stored at $4{ }^{\circ} \mathrm{C}$ in anhydrous THF if not used on the day of purification to avoid hydrolysis and condensation the alkoxysilane functional group.

Synthesis of pTMSPMA/SiO ${ }_{2}$ class II hybrid. pTMSPMA/SiO hybrids were synthesised using the sol-gel process with tetraethyl orthosilicate (TEOS) and PTMSPMA as precursors via the acidic route at room temperature. First, the purified polymer was dried from THF by vacuum distillation using Buchi Rotovapor RII $\left(T_{\text {bath }}=60{ }^{\circ} \mathrm{C}\right.$, nominal pressure $\left.=350 \mathrm{mbar}\right)$. The mass of the polymer was then recorded and pTMSPMA immediately redissolved in ethanol at a molar ratio $R_{\text {ethanol }}=\frac{n_{\text {ethanol }}}{n_{\text {TMSPMA }}}=6$. Meanwhile, in a separate beaker, TEOS was weighed to be further hydrolysed. The mass of TEOS hydrolysed was calculated based on the mass of the polymer

Table 5 Summary of the targeted $M_{n}$ and their corresponding thioglycerol concentration

\begin{tabular}{lrc}
\hline Targeted $M_{\mathrm{w}}(\mathrm{kDa})$ & $\overline{\mathrm{DP}}_{\mathrm{ni}}$ & $R_{0}\left(\times 10^{-3}\right)$ \\
\hline 30 & 120 & 8.3 \\
15 & 60 & 16.6 \\
7.5 & 30 & 33.1 \\
2.5 & 10 & 99.4
\end{tabular}

$\left(m_{\text {polymer }}\right)$ and the desired inorganic to organic mass ratio $\left(I_{\mathrm{h}}\right)$, using the following equation:

$$
\begin{aligned}
I_{\mathrm{h}}= & \frac{m_{\mathrm{SiO}_{2}}+m_{\mathrm{SiO}_{1.5}}}{m \mathrm{SiO}_{2}+m_{\mathrm{SiO}_{1.5}}+m_{\mathrm{Org}}} \Leftrightarrow \\
m_{\mathrm{TEOS}}= & \left(\frac{I_{\mathrm{h}}}{1-I_{\mathrm{h}}} \times \frac{m_{\text {polymer }}}{M_{\mathrm{w}, \mathrm{TMSPMA}}} \times M_{\mathrm{w}, \mathrm{Org}}\right. \\
& \left.-\frac{m_{\mathrm{polymer}}}{M_{\mathrm{w}, \mathrm{TMSPMA}}} \times M_{\mathrm{w}, \mathrm{SiO}_{1.5}}\right) \times \frac{M_{\mathrm{w}, \mathrm{TEOS}}}{M_{\mathrm{w}, \mathrm{SiO}_{2}}}
\end{aligned}
$$

It must be noted that the backbone of the polymer was considered, in this equation, as the organic part of the class II hybrid. Hydrochloric acid and water were added to the beaker relative to the number of alkoxy silane groups taking into account TEOS and pTMSPMA according to the following ratios: $R_{\mathrm{HCl}}=\frac{n_{\mathrm{HCl}}}{n_{\mathrm{SiOR}}}=0.01$ and $R_{\mathrm{H}_{2} \mathrm{O}}=\frac{n_{\mathrm{H}_{2} \mathrm{O}}}{n_{\mathrm{SiOR}}}=1$. However, water from $\mathrm{HCl}$ was subtracted to the final amount of distilled water added. The solution was stirred at $1000 \mathrm{rpm}$ for 30 minutes, allowing TEOS to hydrolysed, after which the purified polymer was poured into the beaker. The mixture was allowed to mix for $30 \mathrm{~s}$ and casted into PTFE containers and subsequently sealed. After 3 days of ageing, the lids were loosened for the solvent to evaporate. pTMSPMA/SiO ${ }_{2}$ monoliths were considered dried when their mass appeared to be stable on the balance.

\subsection{Characterisation}

${ }^{1} \mathbf{H}$ NMR. spectra were recorded in $\mathrm{CDCl}_{3}$ using a Bruker AV-400 spectrometer operating at $400 \mathrm{MHz}$. Spectra were then analysed using MestReNova 7.0 software. Prior integration and chemical shift identification, the baseline was corrected using a built-in Whittaker algorithm and the spectrum calibrated to TMS (tetramethylsilane).

Size exclusion chromatography. Molecular weight characterisation was carried out by size exclusion chromatography using the Viscotek TDA 305 instrument (Malvern instrument, USA) equipped with a Viscotek D6000M and D2500M columns. The TDA module was fitting with a refractive index (RI) detector, a four bridge viscometer (VIS) and a low and right angle laser scattering (LS) detectors. Linear polymethylmethacrylate were applied as a standard for universal calibration. The experimental conditions consisted of dimethylformamide with $0.075 \%$ of lithium bromide as a mobile phase flowing at $0.7 \mathrm{~mL} \mathrm{~min}^{-1}$, $35{ }^{\circ} \mathrm{C}$. A injection volume of $100 \mu \mathrm{L}$ with a concentration varying between 5 and $10 \mathrm{mg} \mathrm{mL}^{-1}$ were used.

Dynamic light scattering. Dynamic light scattering (DLS) was measured on a Malvern Zetasizer (instrument 2000) instrument with a backscattering detection at $173^{\circ}$, equipped with a $\mathrm{He}-\mathrm{Ne}$ laser $(\lambda=632.8 \mathrm{~nm})$.

Thermogravimetry analysis. TGA was performed using a Netzsch sta $449 \mathrm{c}$ in air. The sample was placed in a platinium crucible and heated up to $1000{ }^{\circ} \mathrm{C}$ at $10{ }^{\circ} \mathrm{C} \mathrm{min}^{-1}$.

Skeletal density. The skeletal density was determined by automated helium displacement pycnometry (Ultrapycnometer 1000, QuantaChrome). For each sample, data were acquired 
until 10 consecutive measurements were recorded with a standard deviation inferior to 0.03 .

Acoustic atomic force microscopy. An AFM 5500 microscope (Keysight technologies, previously Agilent) was used for the AFM study in its acoustic mode. An HQ:NSC15/Al BS tip ( $\mu$ masch) was used for the topography and phase images (tip radius of $8 \mathrm{~nm}$, resonance frequency of $325 \mathrm{kHz}$, force constant of $40 \mathrm{~N} \mathrm{~m}^{-1}$ ). The measurements were performed in ambient atmosphere.

Solid state NMR. All ${ }^{29} \mathrm{Si}$ single pulse MAS NMR measurements were performed at 7.0 T using a Varian-Chemagnetics InfinityPlus spectrometer operating at a Larmor frequency of 69.62 MHz. These experiments were performed using a Bruker $7 \mathrm{~mm} \mathrm{HX}$ probe which enabled a MAS frequency of $5 \mathrm{KHz}$ to be implemented. Flip angle calibration was performed on kaolinite from which a $\frac{\pi}{2}$ pulse time of $5.5 \mu$ s duration was measured. All measurements were undertaken with a $\frac{\pi}{2}$ tip angle along with a recycle delay between excitation pulses of $240 \mathrm{~s}$. All ${ }^{29} \mathrm{Si}$ isotropic shifts were reported against the IUPAC recommended primary reference of $\mathrm{Me}_{4} \mathrm{Si}\left(1 \%\right.$ in $\left.\mathrm{CDCl}_{3}, \delta 0.0 \mathrm{ppm}\right)$, via a kaolinite secondary reference from which the resonance exhibits a known shift of -92.0 ppm. $^{48}$ Cross polarised (CP) MAS NMR was also performed to get the chemical shift of each silicon species and used for the deconvolution of the single pulse spectra. The CP spectra are available in ESI $\dagger$ (S7).

Nanoindentation. Measurement were performed using a NanoTest Vantage (Micro Materials Ltd, UK) mounted with a Berkovich pyramidal tip. Prior measurement, samples were mounted in epoxy resin with a clearance of at least $5 \mathrm{~mm}$ between the bottom of the sample and the bottom of the resin. Load was applied on the sample at a rate of $5 \mathrm{mN} \mathrm{s}^{-1}$ to a maximum load of $50 \mathrm{mN}$. The tips was unloaded at a rate of $10 \mathrm{mN} \mathrm{s}^{-1}$ after a dwell of $20 \mathrm{~s}$, a rate of $15 \mathrm{mN} \mathrm{s}^{-1}$ down to $5 \mathrm{mN}$ when a final dwell for $60 \mathrm{~s}$ was also applied to determine the thermal drift contribution of the indentation system to total displacement measured by a capacitive transducer.

\section{Acknowledgements}

The authors wish to thank EPSRC (EP/I020861/1) for funding. J. V. H. thanks the EPSRC and the University of Warwick for partial funding of the solid-state NMR infrastructure at Warwick, and acknowledge additional support for this infrastructure obtained through Birmingham Science City: Innovative Uses for Advanced Materials in the Modern World (West Midlands Centre for Advanced Materials Projects 1 and 2), with support from Advantage West Midlands (AWM) and partial funding by the European Regional Development Fund (ERDF).

\section{References}

1 B. M. Novak, Adv. Mater., 1993, 5, 422-432.

2 O. Mahony, O. Tsigkou, C. Ionescu, C. Minelli, L. Ling, R. Hanly, M. E. Smith, M. M. Stevens and J. R. Jones, Adv. Funct. Mater., 2010, 20, 3835-3845.
3 J. D. Mackenzie, Q. Huang and T. Iwamoto, J. Sol-Gel Sci. Technol., 1996, 7, 151-161.

4 F. Mammeri, E. L. Bourhis, L. Rozes and C. Sanchez, J. Mater. Chem., 2005, 15, 3787-3811.

5 M. S. Oliver, G. Dubois, M. Sherwood, D. M. Cage and R. H. Dauskardt, Adv. Funct. Mater., 2010, 20, 2884-2892.

6 P. Innocenzi, G. Brusatin and F. Babonneau, Chem. Mater., 2000, 3726-3732.

7 S. C. Warren, M. R. Perkins, A. M. Adams, M. Kamperman, A. A. Burns, H. Arora, E. Herz, T. Suteewong, H. Sai, Z. Li, J. Werner, J. Song, U. Werner-Zwanziger, J. W. Zwanziger, M. Gratzel, F. J. DiSalvo and U. Wiesner, Nat. Mater., 2012, 11, 460-467.

8 M. R. N. Monton, E. M. Forsberg and J. D. Brennan, Chem. Mater., 2011, 24, 796-811.

9 K. Tsuru, C. Ohtsuki, A. Osaka, T. Iwamoto and J. D. Mackenzie, J. Mater. Sci.: Mater. Med., 1997, 8, 157-161.

10 S.-J. Choi, T.-H. Kwon, D.-I. Moon, D. J. Beak, M.-L. Seol, J. P. Duarte and Y.-K. Choi, ACS Appl. Mater. Interfaces, 2011, 3, 4552-4556.

11 X. Dieudonnée, V. Montouillout, E. Jallot, F. Fayon and J. Lao, Chem. Commun., 2014, 50, 8701-8704.

12 S.-H. Rhee and J.-Y. Choi, J. Am. Ceram. Soc., 2002, 85, 1318-1320.

13 L. Ren, K. Tsuru, S. Hayakawa and A. Osaka, J. Non-Cryst. Solids, 2001, 285, 116-122.

14 V. Mellon, D. Rinaldi, E. Bourgeat-Lami and F. D'agosto, Macromolecules, 2005, 38, 1591-1598.

15 J. Du and Y. Chen, Macromolecules, 2004, 37, 6322-6328.

16 F. Pardal, V. Lapinte and J.-J. Robin, Eur. Polym. J., 2009, 45, 1198-1207.

17 L. S. Connell, F. Romer, M. Suárez, E. M. Valliant, Z. Zhang, P. D. Lee, M. E. Smith, J. V. Hanna and J. R. Jones, J. Mater. Chem. B, 2014, 2, 668.

18 L. Gabrielli, L. S. Connell, L. Russo, J. Jiménez-Barbero, F. Nicotra, L. Nicotra and J. R. Jones, RSC Adv., 2014, 4, 1841.

19 B. K. Coltrain, C. J. T. Landry, J. M. O'Reilly, A. M. Chamberlain, G. A. Rakes, J. S. Sedita, L. W. Kelts, M. R. Landry and V. K. Long, Chem. Mater., 1993, 5, 1445-1455.

20 M. R. Landry, B. K. Coltrain, C. J. T. Landry and J. M. O'Reilly, J. Polym. Sci., Part B: Polym. Phys., 1995, 33, 637-655.

21 D. E. Rodrigues, B. G. Risch and G. L. Wilkes, Chem. Mater., 1997, 9, 2709-2719.

22 R. Ravarian, H. Wei, A. Rawal, J. Hook, W. Chrzanowski and F. Dehghani, J. Mater. Chem. B, 2013, 1, 1835-1845.

23 M. Li, R. L. Harbron, J. V. M. Weaver, B. P. Binks and S. Mann, Nat. Chem., 2013, 5, 529-536.

24 T. Arai, N. Sawatari, T. Yoshizaki, Y. Einaga and H. Yamakawa, Macromolecules, 1996, 29, 2309-2314.

25 L. L. Hench and J. K. West, Chem. Rev., 1990, 30, 30-72.

26 C. J. Brinker and G. W. Scherer, Sol-Gel Science: The Physics and Chemistry of Sol-Gel Processing, Academic Press, San Diego, 1990.

27 R. K. Iler, The Chemistry of Silica, Wiley-Interscience, New York, 1979. 
28 S. N. Magonov, V. Elings and M.-H. Whangbo, Surf. Sci., 1997, 375, L385-L391.

29 J. P. Cleveland, B. Anczykowski, A. E. Schmid and V. B. Elings, Appl. Phys. Lett., 1998, 72, 2613.

30 R. Garcia, C. J. Gomez, N. F. Martinez, S. Patil, C. Dietz and R. Magerle, Phys. Rev. Lett., 2006, 97, 016103.

31 M. L. Oyen and R. F. Cook, J. Mech. Behav. Biomed. Mater., 2009, 2, 396-407.

32 F. Mammeri, L. Rozes, E. L. Bourhis and C. Sanchez, J. Eur. Ceram. Soc., 2006, 26, 267-272.

33 F. Mammeri, E. L. Bourhis, L. Rozes and C. Sanchez, J. Eur. Ceram. Soc., 2006, 26, 259-266.

34 F. Mammeri, E. L. bourhis, L. Rozes, C. Sanchez, A. Huignard and D. Lefevre, J. Non-Cryst. Solids, 2004, 345, 610-614.

35 W. C. Oliver and G. M. Pharr, J. Mater. Res., 1992, 7, 1564-1583. 36 M. L. Oyen and R. F. Cook, J. Mater. Res., 2003, 18, 139-150.

37 W. N. Findley, J. S. Lai and K. Onaran, Creep and relaxation of nonlinear viscoelastic materials, North-Holland Publishing Company, 1976.

38 J. Alvarado-Rivera, J. Muñoz-Saldaña and R. Ramrez-Bon, Thin Solid Films, 2011, 519, 5528-5534.

39 G. Poologasundarampillai, B. Yu, O. Tsigkou, D. Wang, F. Romer, V. Bhakhri, F. Giuliani, M. M. Stevens,
D. S. McPhail, M. E. Smith, J. V. Hanna and J. R. Jones, Chem. - Eur. J., 2014, 20, 8149-8160.

40 J. Menčík, D. Munz, E. Quandt, E. R. Weppelmann and M. V. Swain, J. Mater. Res., 1997, 12, 2475.

41 J. M. Antunes, J. V. Fernandes, N. A. Sakharova, M. C. Oliveira and L. F. Menezes, Int. J. Solids Struct., 2007, 44, 8313-8334.

42 Y. Wei, D. Jin, J. Xu, G. Baran and K.-Y. Qui, Polym. Adv. Technol., 2001, 12, 361-368.

43 F. Mauri, A. Pasquarello, B. G. Pfrommer, Y.-G. Yoon and S. G. Louie, Phys. Rev. B: Condens. Matter Mater. Phys., 2000, 62, R4786.

44 I. Halasz, A. Kierys, J. Goworek, H. Liu and R. E. Patterson, J. Phys. Chem. C, 2011, 115, 24788-24799.

45 M. Criado, I. Sobrados and J. Sanz, Prog. Org. Coat., 2014, 880-891.

46 Y. Abe, Y. Honda and T. Gunji, Appl. Organomet. Chem., 1998, 12, 749-753.

47 H. Fan, C. Hartshorn, T. Buchheit, D. Tallant, R. Assink, R. Simpson, D. J. Kissel, D. J. Lacks, S. Torquato and C. J. Brinker, Nat. Mater., 2007, 6, 418.

48 R. K. Harris, E. D. Becker, S. M. C. D. Menezes, R. Goodfellow and P. Granger, Pure Appl. Chem., 2001, 73, 1795. 